\title{
Interações educador-crianças no contexto de creches públicas e privadas
}

\author{
Ellis Santos, Deborah Ramos \& Nádia Salomão
}

Resumo:

Este artigo objetiva analisar as interações educador-crianças em creches públicas e privadas. É um estudo qualitativo, tendo como participantes 24 educadoras e 95 crianças com idade entre 24 e 30 meses. As interações educadora-crianças foram observadas sistematicamente e filmadas em contextos poliádicos de leitura/apresentação de histórias infantis. Para a transcrição dessas observações e o levantamento da frequência das categorias interacionais, utilizaram-se, no primeiro caso, as normas operacionais do CHAT (Codes for the Human Analysis of Transcripts) e, no segundo caso, o CLAN (Computerized Language Analysis), sendo ambos componentes do programa computacional CHILDES (Child Language Data Exchange System). Assim, sobre os Estilos comunicativos das educadoras, prevaleceu o uso das Requisições nos dois grupos de educadoras, sobretudo as Requisições de resposta geral e as Requisições de resposta específica. Destacaram-se também os Assertivos e os Diretivos de atenção entre as educadoras das creches públicas e das creches particulares, sendo que os Diretivos de atenção foram mais frequentes nas creches particulares. Com relação à análise dos Comportamentos comunicativos infantis, predominou a linguagem verbal nos dois grupos de crianças. Desse modo, almeja-se, com esta pesquisa, subsidiar a prática do educador de creche no contexto das interações com a criança.

Palavras-Chave:

creches; linguagem; desenvolvimento infantil. 


\title{
Educator-children interactions in the context of public and private day care centers
}

\begin{abstract}
This article aims to analyze educator-child interactions in public and private day care centers. It is a qualitative study, involving 24 educators and 95 children aged between 24 and 30 months. The educator-child interactions were systematically observed and filmed in polyadic contexts of reading/presenting children's stories. For the transcription of these observations and the survey the frequency of interactional categories were used in the first case, the operating rules of Codes for the Human Analysis of Transcripts (CHAT) and in the second case, the Computerized Language Analysis (CLAN), both components of the computer program Child Language Data Exchange System (CHILDES). Thus, on the communicative Styles of educators, the use of the Requisitions in the two groups of educators prevailed, especially the General Response Requisitions and the Specific Response Requisitions. The Assertive and the Directives of attention among the educators of the public day-care centers and of the private daycare centers were also highlighted, and the Directives of attention were more frequent in the private day-care centers. With regard to the analysis of children's communicative behaviors, verbal language predominated in both groups of children. Thus, this research aims at subsidizing the practice of the day care educator in the context of interactions with the child.
\end{abstract}

Keywords: child day care; language; child development.

\section{Interactions éducateur-enfants dans le contexte des cruces publiques et privées}

Résumé: Cet article vise à analyser les interactions enfants des enseignants dans les écoles maternelles publiques et privées. II est une étude qualitative, dont les participants 24 enseignants et 95 enfants âgés de 24 à 30 mois. Les interactions éducateur-enfant ont été systématiquement observées et filmées dans des contextes polyadiques de lecture/présentation d'histoires d'enfants. Pour la transcription de ces observations et l'étude de la fréquence des catégories interactionnelles, dans le premier cas, les normes opérationnelles du CHAT (Codes for the Human Analysis of Transcripts) et, dans le second cas, le CLAN (Computerized Language Analysis) étant les deux composantes du programme informatique CHILDES (Child Language Data Exchange System). Ainsi, sur les styles de communication des éducateurs, a prévalu l'utilisation des réquisitions dans les deux groupes d'éducateurs, en particulier les demandes de réponse globale et demande une réponse spécifique. Les affirmations et les directives d'attention parmi les éducateurs des crèches et des garderies privées ont également été soulignées, et les directives d'attention étaient plus fréquentes dans les crèches privées. En ce qui concerne l'analyse des comportements communicatifs des enfants, le langage verbal prédomine chez les deux groupes d'enfants. Ainsi, cette recherche vise à subventionner la pratique de l'éducateur en garderie dans le cadre des interactions avec l'enfant.

Mots-clés: crèches; langue; développement de l'enfant.

\section{interacciones educador/niños en el contexto de guarderías infantiles públicas y privadas}

Resumen: Este artículo objetiva analizar las interacciones educador-niños en guarderías públicas y privadas. Es un estudio cualitativo, teniendo como participantes 24 educadoras y 95 niños con edad entre 24 y 30 meses. Las interacciones educadora-niños fueron observadas sistemáticamente y filmadas en contextos poliádicos de lectura/ presentación de historias infantiles. Para la transcripción de estas observaciones y el levantamiento de la frecuencia de las categorías interactivas, se utilizaron, en el primer caso, las normas operacionales del CHAT (Codes for the Human Analysis of Transcripts) y, en el según caso, el CLAN (Computerized Language Analysis), siendo ambos componentes del programa computacional CHILDES (Child Language Data Exchange System). Así, sobre los Estilos comunicativos de las educadoras, prevaleció el uso de las Solicitudes en los dos grupos de educadoras, sobre todo las Solicitudes de respuesta general y las Solicitudes de respuesta específica. Se destacaron también los Asertivos y los Directivos de atención entre las educadoras de las guarderías públicas y de las guarderías privadas, siendo que los Directivos de atención fueron más frecuentes en las guarderías privadas. Con respecto al análisis de los Comportamientos comunicativos infantiles, predominó el lenguaje verbal en los dos grupos de niños. De este modo, se anhela, con esta investigación, subsidiar la práctica del educador de guardería en el contexto de las interacciones con el niño.

Palabras Clave: jardines infantiles; lenguaje; desarrollo infantil. 


\section{Introdução}

O desenvolvimento humano pode ser compreendido como um processo dialógico, dinâmico, histórico e cultural que prepara o indivíduo, através das trocas sociais, para novas formas de conhecimento. Para tanto, consideramos as contribuições oriundas da teoria sócio-histórica de Vigotski, que defende uma compreensão de desenvolvimento baseada na concepção de um organismo ativo, cujo pensamento é construído paulatinamente num ambiente que é histórico e, em essência, social (Vigotski, 2007).

Desse modo, a partir dos pressupostos vigotskianos, a Perspectiva da Interação Social dos Estudiosos da Linguagem identifica a interação adulto-criança como um fator norteador dos primeiros contatos da criança com a linguagem, pois considera que os adultos e as crianças configuram-se como parceiros ativos na interação, promovendo situações mútuas de acesso à comunicação (Snow, 1997; Salomão, 2012; Luo, Snow \& Chang, 2012).

Nessa perspectiva, a compreensão da relação que envolve as trocas sociais e o desenvolvimento linguístico faz-se fundamental, dentre outros fatores, para se verificar os estilos linguísticos e os comportamentos comunicativos apresentados nas interações entre adultos e crianças (Salomão, 2010; Ramos \& Salomão, 2012). Pois, a criança, na sua relação ativa com o mundo, possui diferentes parceiros e compartilha de inúmeras situações de interação, visto que ela interage não só com a mãe, mas, também, relaciona-se com outros agentes de socialização. Assim, consideram-se as interações adulto-criança e o contexto da creche como cada vez mais presentes nesse processo, ou seja, a creche preconiza uma mudança de referenciais, na qual a criança pode, desde muito cedo, interagir com "outros sociais" (Pessoa \& Seidl de Moura, 2008; Santos, Ramos \& Salomão, 2015; Ramos \& Salomão, 2016).

Partindo dessa premissa, considera-se fundamental que a análise dessas interações possa ser feita no contexto de creches públicas e privadas, tendo em vista o fato desses espaços constituírem-se como uma forma representativa de cuidado às crianças pequenas (Delgado, 2015); a qualidade das experiências sociocomunicativas oferecidas à criança pelo educador - a partir de aspectos como o input linguístico desse educador e seu nível educacional - ser considerada um potencializador do seu desenvolvimento; e as concepções de desenvolvimento infantil veiculadas por esses educadores representarem possíveis indicadores de como essas interações ocorrem e podem predizer a respeito da promoção do desenvolvimento da linguagem da criança (Santos et al., 2015).

Desse modo, o presente estudo objetivou analisar as interações educador-crianças no contexto de creches públicas e privadas, considerando, especificamente, os estilos comunicativos utilizados pelos educadores e os comportamentos comunicativos infantis apresentados nessas interações. 


\section{Método}

Estudo caracterizado como qualitativo que procura descrever os estilos comunicativos utilizados pelas educadoras e os comportamentos comunicativos infantis apresentados nas interações educadora-crianças, e que, por isso, também recorre à quantificação de alguns dados que auxiliam na descrição das frequências das categorias e subcategorias obtidas. Conforme Minayo (2010), a pesquisa do tipo qualitativa possibilita a compreensão de um determinado fenômeno em sua profundidade.

Ressalta-se que esta pesquisa foi submetida ao Comitê de Ética do Centro de Ciências da Saúde da Universidade Federal da Paraíba (UFPB) e aprovada sob o protocolo $n^{\circ}$ 0232B.

\section{Participantes}

Os participantes corresponderam a 24 educadoras e a 95 crianças, acompanhadas pelas mesmas em situações de uma atividade estruturada por essas profissionais, nas turmas do Maternal I de três creches da rede pública e três creches da rede privada da cidade de Campina Grande-PB. Esse número de educadoras foi dividido igualmente entre os dois tipos de creche, ou seja, 12 pertencentes às creches públicas e 12 pertencentes às creches particulares. Explica-se a amostra ser predominantemente de educadoras devido ao fato de não se ter encontrado participantes do sexo masculino como responsáveis pelas turmas de crianças nesses locais de pesquisa.

Outro critério estabelecido para a participação no estudo se refere à idade das crianças, situada entre 24 e 30 meses de idade, por esta ser uma faixa etária considerada fundamental para a formulação das suas primeiras pequenas frases (Rescorla, 1989). Ou seja, é um período considerado crítico para o desenvolvimento da linguagem expressiva (Kelly \& Bailey, 2012). Nessa premissa, as observações envolveram a participação de 95 crianças, sendo 72 das creches públicas e 23 crianças das creches particulares.

A idade das educadoras pesquisadas das creches públicas variou entre 22 e 46 anos $(M=33,66)$, e a idade das educadoras das creches particulares variou entre $22 \mathrm{e}$ 37 anos $(M=26,58)$. Um total de 83\% das educadoras das creches públicas tinha Nível Superior Completo e as demais (17\%) tinha Nível Superior Incompleto, enquanto que o Nível de Escolaridade das educadoras das creches particulares se dividia entre Nível Superior Incompleto (42\%), Nível Superior Completo (33\%) e Nível Médio Completo (25\%). 


\section{Instrumentos/Procedimentos para a coleta e análise dos dados}

A coleta de dados se estruturou a partir da aplicação dos seguintes instrumentos: questionário sociodemográfico e registro das interações educadora-crianças a partir da observação das mesmas. O primeiro deles caracterizou o grupo de educadoras quanto à idade, ao sexo e ao nível de escolaridade. Foi realizado um levantamento por frequência desses dados sociodemográficos, os quais serviram para melhor caracterizar o perfil da população pesquisada, conforme descrito no item anterior.

Por sua vez, as interações educadora-crianças foram observadas sistematicamente e filmadas em contextos poliádicos de leitura/apresentação de histórias infantis. Para analisar o material coletado e transcrito a partir dessas observações foram elaboradas categorias interacionais, baseadas nos comportamentos que emergiram a partir da observação das interações, dos objetivos da pesquisa e da literatura. Destaca-se que as categorias foram estruturadas de forma mutuamente exclusiva, ou seja, cada um dos comportamentos comunicativos verbais e não verbais foram classificados em apenas uma categoria, que correspondia, conforme a avaliação de três juízes, àquela que correspondia à principal função comunicativa do comportamento.

Dessa maneira, a transcrição das observações das interações filmadas seguiu as normas do CHAT (Codes for the Human Analysis of Transcripts), e a codificação dos comportamentos comunicativos verbais e não verbais das educadoras e das crianças, seguida do levantamento da frequência das categorias interacionais, foi realizada a partir das normas do CLAN (Computorized Language Analysis), sendo ambos componentes do programa computacional CHILDES (Child Language Data Exchange System), o qual, conforme Sokolov e Snow (1994), é composto por interfaces que visam facilitar a troca de dados entre diferentes pesquisadores, aumentar a fidedignidade das transcrições e automatizar o processo de análise de dados.

\section{Resultados e discussão}

Os resultados aqui apresentados correspondem, inicialmente, às frequências e ao percentual dos estilos comunicativos utilizados pelas educadoras: 
Tabela 1 - Estilos comunicativos utilizados pelas educadoras e dirigidos às crianças nos contextos de interação poliádica das creches públicas e das creches particulares

\begin{tabular}{|c|c|c|c|c|c|c|c|}
\hline \multirow[t]{2}{*}{ CATEGORIAS } & \multirow[t]{2}{*}{ SUBCATEGORIAS } & \multicolumn{2}{|c|}{$\begin{array}{l}\text { CONTEXTO } \\
\text { POLIÁDICO/ } \\
\text { CRECHES } \\
\text { PÚBLICAS }\end{array}$} & \multicolumn{2}{|c|}{$\begin{array}{c}\text { CONTEXTO } \\
\text { POLIÁDICO/ } \\
\text { CRECHES } \\
\text { PARTICULARES }\end{array}$} & \multicolumn{2}{|c|}{ TOTAL } \\
\hline & & $\mathrm{F}$ & $\%$ & $\mathrm{~F}$ & $\%$ & $\mathrm{~F}$ & $\%$ \\
\hline \multirow[t]{5}{*}{ Feedbacks } & Feedback de correção & 16 & 1,23 & 16 & 1,05 & 32 & 1,12 \\
\hline & Feedback de confirmação & 54 & 4,17 & 77 & 4,94 & 131 & 4,6 \\
\hline & Feedback de aprovação & 8 & 0,62 & 14 & 0,89 & 22 & 0,78 \\
\hline & Feedback de desaprovação & 6 & 0,46 & 15 & 0,96 & 21 & 0,73 \\
\hline & Feedback de resposta à questão & 12 & 0,93 & 11 & 0,7 & 23 & 0,8 \\
\hline TOTAL & & 96 & 7,41 & 133 & 8,54 & 229 & 8,03 \\
\hline \multirow[t]{5}{*}{ Requisições } & Requisição de resposta geral & 216 & 16,69 & 253 & 16,25 & 469 & 16,45 \\
\hline & Requisição de resposta específica & 148 & 11,43 & 169 & 10,85 & 317 & 11,11 \\
\hline & Requisição de sugestão & 66 & 5,10 & 38 & 2,44 & 104 & 3,64 \\
\hline & Requisição de esclarecimento & 7 & 0,54 & 19 & 1,22 & 26 & 0,91 \\
\hline & Requisição de complementação & 34 & 2,63 & 51 & 3,27 & 85 & 3 \\
\hline TOTAL & & 471 & 36,39 & 530 & 34,03 & 1001 & 35,11 \\
\hline Assertivos & & 271 & 20,94 & 297 & 19,07 & 568 & 20 \\
\hline Reformulações & & 11 & 0,85 & 29 & 1,86 & 40 & 1,4 \\
\hline \multirow[t]{3}{*}{ Diretivos } & Diretivo de atenção & 150 & 11,6 & 263 & 16,89 & 413 & 14,48 \\
\hline & Diretivo de controle & 29 & 2,24 & 54 & 3,46 & 83 & 2,91 \\
\hline & Diretivo de instrução precisa & 12 & 0,92 & 27 & 1,74 & 39 & 1,31 \\
\hline TOTAL & & 191 & 14,76 & 344 & 22,09 & 535 & 18,7 \\
\hline Cantar & & 13 & 1 & 35 & 2,24 & 48 & 1,68 \\
\hline \multirow[t]{2}{*}{ Uso do livro } & Leitura do livro & 47 & 3,65 & 23 & 1,47 & 70 & 2,45 \\
\hline & Vocalização com o livro & 126 & 9,75 & 98 & 6,3 & 224 & 7,85 \\
\hline TOTAL & & 173 & 13,4 & 121 & 7,77 & 294 & 10,31 \\
\hline \multirow{3}{*}{$\begin{array}{l}\text { Gestos } \\
\text { comunicativos }\end{array}$} & Gesto de apontar & 57 & 4,4 & 61 & 9,91 & 118 & 4,15 \\
\hline & Gesto de afirmação & 04 & 0,3 & 05 & 0,33 & 9 & 0,31 \\
\hline & Gesto de negação & 07 & 0,55 & 02 & 0,16 & 9 & 0,31 \\
\hline TOTAL & & 68 & 5,25 & 68 & 4,4 & 136 & 4,77 \\
\hline TOTAL & & 1.294 & 100 & 1.557 & 100 & 2.851 & 100 \\
\hline
\end{tabular}

Fonte: Santos, E.R.F. (2012). Concepções de Desenvolvimento Infantil e Estilos Comunicativos nas Interações Educador-Criança (Tese de doutoramento, Departamento de Psicologia, Universidade Federal da Paraíba, João Pessoa, Brasil). 
A partir da Tabela 1 observa-se que os Estilos comunicativos utilizados pelas educadoras originaram 8 categorias gerais, as quais se desdobraram em 18 subcategorias. Desse modo, verificou-se a predominância das Requisições ( $f=1001 ; 35,11 \%$ ) enquanto estilos comunicativos utilizados tanto pelas educadoras das creches públicas ( $f=471 ; 36,39 \%)$ quanto das privadas ( $f=530 ; 34,03 \%)$, destacando-se o uso das Requisições de resposta geral ( $\mathrm{f}=469 ; 16,45 \%)$ e das Requisições de resposta específica $(f=317 ; 11,11 \%)$ nos dois grupos.

Nessa premissa, Salomão (2010) define as Requisições de resposta geral como questões elaboradas pelo adulto as quais remetem à solicitação de informações, por parte das crianças, sobre aspectos como localização, identidade de um objeto, evento ou determinada situação, enquanto que as Requisições de resposta específica caracterizam-se por questões em que o adulto solicita das crianças confirmações ou negações em relação a um enunciado prévio. Em vista disso, observa-se que, principalmente, as Requisições de resposta geral possuem um caráter facilitador do desenvolvimento linguístico infantil porque conferem às crianças a oportunidade de aprimorar suas habilidades comunicativas, uma vez que requerem respostas mais amplas e melhor estruturadas, ao passo que Requisições de resposta específica suscitam respostas mais simples, restritas ao sim ou não (Rivera, Girolametto, Greenberg \& Weitzman, 2005).

Estudos realizados em creches, tais como os de Hargrav e Sénéchal (2000), Rivera et al. (2005), Ramos e Salomão (2012), Milburn, Girolametto, Weitzman e Greenberg (2013) e Ramos e Salomão (2016), revelaram resultados diferentes dos encontrados no presente estudo, visto que os autores supracitados verificaram uma prevalência do uso de Requisições de resposta específica em contextos de interação poliádica, além de representar menor qualidade e quantidade de atenção.

Embora a literatura tenha apresentado esses resultados, no presente estudo houve uma prevalência do uso das Requisições de resposta geral entre as educadoras das creches públicas e particulares nos contextos de interação poliádica. Pode-se inferir que isso ocorreu devido a características específicas dos contextos onde os dados foram coletados, tais como o tipo de atividade de Contar e recontar a história, na qual as educadoras, de maneira geral, não se restringiam a só relatar a história, mas também buscavam recontá-la, fazendo questionamentos às crianças. Destaca-se, também, que enquanto a história era contada surgiam questionamentos das educadoras voltados para as crianças, buscando saber o que achavam que poderia acontecer no transcorrer da narrativa. Além disso, observou-se que a presença considerável de falas espontâneas por parte das crianças, iniciando situações de interação, ocasionou situações que suscitavam a elaboração de questionamentos por parte das educadoras, estabelecendo maiores períodos de diálogos. 
Possivelmente, esse formato de Contar e recontar a história, adotado como uma prática capaz de promover a participação das crianças em contextos interativos, tem relação com o fato de a maior parte das educadoras pesquisadas ter cursado ou estar cursando formação de nível superior em Pedagogia, o que sugere que essas profissionais possuem o conhecimento sobre como manejar o contexto de leitura de história na perspectiva de facilitar a participação e a comunicação das crianças no mesmo.

O segundo estilo comunicativo a se destacar foram os Assertivos, obtendo um nível de incidência bastante semelhante tanto nas creches públicas ( $f=271 ; 20,94 \%$ ) quanto nas particulares ( $f=297 ; 19,07 \%$ ). Com relação à prevalência desse estilo, destaca-se que o mesmo costuma ser associado a contextos de leitura e narrativa de histórias, tais como os que foram utilizados no presente estudo, uma vez que os assertivos referem-se a enunciados que visam descrever situações e ações na tentativa de fornecer informações à criança sobre propriedades, localizações e possessões (Tamis-LeMonda, Baumwell \& Cristofaro, 2012).

O estudo de Girolametto e Weitzman (2002), que versa sobre o input linguístico de responsividade usado por educadores com crianças mais novas e pré-escolares em dois contextos naturais de atividade (um de brincadeira com massa de modelar e o outro de leitura de livros), também identificou o uso acentuado de assertivos, pelas educadoras, no contexto poliádico de leitura de livro. Para os autores desse estudo, as possíveis explicações podem estar no fato de as educadoras, geralmente, terem a expectativa de que as crianças vão apenas escutar, ficar atentas e responder a questões específicas sobre o conteúdo do livro; como também as educadoras tendem a compreender a leitura de livro como uma atividade puramente didática ou instrucional, logo, buscariam informar mais e descrever itens da história às crianças.

Em relação aos Assertivos, destaca-se, também, que os mesmos vieram em determinadas situações acompanhados de Gestos comunicativos, como apontar, numa forma de fornecer às crianças uma inter-relação entre o objeto e a informação expressa, por exemplo. Esses Gestos comunicativos referem-se a expressões gestuais usadas pelas educadoras para interagir com as crianças, e se configuram entre os estilos comunicativos menos frequentes entre os grupos de educadoras ( $f=136 ; 4,77 \%$ ), mas que aparecem bastante associados aos Assertivos e aos Diretivos.

No conjunto dos estilos comunicativos apresentados às crianças, os Diretivos foram o terceiro estilo a prevalecer em ambos os grupos de educadoras ( $f=535 ; 18,7 \%$ ), sendo que as educadoras das creches públicas usaram o correspondente a 191 Diretivos $(14,76 \%)$ e as educadoras das creches particulares usaram um quantitativo maior de Diretivos ( $f=344 ; 22,09 \%$ ).

Conforme Stich, Girolametto, Johnson, Cleave e Chen (2013), os Diretivos são expressões comunicativas que podem ser interpretadas como comandos ou instruções que possuem um componente imperativo interpretável que dirige a atenção, as 
verbalizações e/ou as ações da criança. Esses estilos diretivos são de diversos tipos e exercem influência diferenciada sobre o desenvolvimento linguístico infantil (Girolametto, Weitzman, Lieshout \& Duff, 2000; Ramos \& Salomão, 2016). Nessa premissa, a análise dos tipos específicos de Diretivos das educadoras dirigidos às crianças revelou que os Diretivos de atenção foram os mais utilizados pelos dois grupos de educadoras, sobretudo pelas educadoras das creches particulares ( $f=263 ; 16,89 \%)$ quando comparadas com as educadoras das creches públicas ( $f=150 ; 11,6 \%)$.

A prevalência dos Diretivos em contextos coletivos, como identificado no presente estudo, pode se dar pelo fato de serem contextos de interação onde os Diretivos costumam favorecer o manejo do grupo e o controle dos comportamentos das crianças, promovendo, ao mesmo tempo, interação e segurança (Girolametto, Weitzman \& Greenberg, 2003; Milburn et al., 2013).

Quanto à elevada frequência dos Diretivos de atenção pelos dois grupos de educadoras, isso pode indicar diversas intenções comunicativas por parte das educadoras, e não apenas a intenção de controle de comportamento das crianças, uma vez que os Diretivos de controle surgiram num quantitativo bem menor ( $f=83 ; 2,91 \%)$. Nessa premissa, o estudo de Girolametto et al. (2000) considera que o papel específico do input linguístico Diretivo na aquisição da linguagem não é definido claramente pelos teóricos sociointeracionistas e que os Diretivos de atenção podem ser vistos como capazes de possibilitar a participação das crianças nas interações, bem como de favorecer o desenvolvimento linguístico de crianças mais novas ou que ainda possuem pouca habilidade comunicativa.

Desta feita, os dados do presente estudo indicam que, além de terem demonstrado esse caráter de promover a interação, estabelecendo turnos maiores de engajamento entre educadoras e crianças nos contextos poliádicos da atividade de Contar e recontar a história, os Diretivos de atenção tiveram também o papel de controle de comportamento das crianças, principalmente por parte das educadoras das creches particulares. Esse aspecto remete ao fato de que existem controvérsias quanto ao uso dos Diretivos, devido a estes não serem comumente associados à promoção do desenvolvimento linguístico - considerando que se trata de um estilo comunicativo que costuma ser considerado mais restritivo por, geralmente, não promover a extensão do diálogo (Stich et al., 2013).

Pode-se supor que isso ocorreu devido a determinados aspectos, tais como: embora os grupos de crianças nas três creches particulares fossem menores do que os das públicas, as educadoras das creches particulares demonstraram mais dificuldades no manejo dos grupos durante a atividade de leitura, por se deterem mais aos aspectos de manutenção da disciplina das crianças do que ao estímulo à participação das mesmas na interação; o uso com maior destaque de todas as subcategorias de Diretivos pelas educadoras das creches particulares; além disso, observou-se que o 
gesto de apontar, cujo uso costuma se associar ao comportamento de direcionar a atenção, também prevaleceu entre as educadoras das creches privadas ( $f=61 ; 9,91 \%$ ) em relação às educadoras das creches públicas ( $f=57 ; 4,4 \%$ ). Nessa premissa, o estudo de Girolametto et al. (2000) considera haver certa associação entre a realização da atividade de leitura de livros em contextos coletivos e o uso considerável de diretivos pelos educadores, visando o controle de comportamento das crianças.

No que tange à categoria Uso do livro, esta se desdobra nas subcategorias Leitura do livro e Vocalização com o livro. Vale destacar que, embora essa categoria de estilo comunicativo não esteja entre os estilos geralmente estudados pela literatura da área, é importante citá-la enquanto categoria que emergiu a partir do próprio tipo de atividade desenvolvida com as crianças, de Contar e recontar a história, e que passou a se configurar como uma forma de promover a interação. O estudo de Ramos e Salomão (2012) é um referencial na identificação dessa categoria entre seus dados de pesquisa.

Nessa premissa, verifica-se que o Uso do livro recebe certo destaque dos dois grupos de educadoras ( $f=294 ; 10,31 \%)$, sobretudo a subcategoria Vocalização com o livro, que se destacou mais entre as educadoras das creches públicas ( $f=126 ; 9,75 \%)$ do que entre as educadoras das creches particulares $(f=98 ; 6,3 \%)$. Essa subcategoria refere-se a situações em que a educadora não apenas conta a história tal qual está no livro, como uma leitura meramente didática, mas, sim, recorre a modificações no contexto da história e busca vocalizar como se fosse um dos personagens (Ramos \& Salomão, 2012). Observa-se que esse tipo de estratégia é importante porque favorece uma maior interação por parte das crianças, além de fazer com que as educadoras recorram menos aos Diretivos de atenção, como foi o caso das educadoras das creches públicas.

No que diz respeito aos Feedbacks e às Reformulações, que, juntamente com as Requisições, são estilos comunicativos associados à promoção do desenvolvimento linguístico infantil (Salomão, 2012; Ramos \& Salomão, 2012; Milburn et al., 2013), observa-se que ambos estão entre as menores frequências de categorias apresentadas nos dois grupos de educadoras. Esses dados corroboram com o estudo de Hargrav e Sénéchal (2000), que também apontou uma menor frequência de Feedbacks e Reformulações nos contextos de interação poliádica.

No entanto, vale destacar os tipos de Feedbacks que se sobressaíram no presente estudo, tanto entre as educadoras das creches públicas quanto das privadas. Esses foram os Feedbacks de confirmação, que correspondem a enunciados do adulto repetindo a resposta da criança, perguntando para confirmar, visando a estimular a comunicação das crianças; e os Feedbacks de correção, que podem ser vistos de maneira mais ampla, porque geralmente o adulto apresenta um enunciado de correção para a verbalização incorreta da criança, sem dizer que ela estava errada. O uso maior 
desses tipos de Feedbacks pode estar relacionado ao fato de terem predominado as Requisições no contexto geral dos estilos comunicativos utilizados pelas educadoras.

Assim, realizada essa discussão sobre os estilos comunicativos utilizados pelas educadoras, segue-se com os resultados e discussão sobre os tipos de comportamentos comunicativos apresentados pelas crianças das creches pesquisadas, conforme Tabela 2:

Tabela 2 - Comportamentos comunicativos apresentados pelas crianças nos contextos de interação poliádica das creches públicas e das creches particulares

\begin{tabular}{|c|c|c|c|c|c|c|}
\hline \multirow[t]{2}{*}{ CATEGORIAS } & \multicolumn{2}{|c|}{$\begin{array}{l}\text { CONTEXTO } \\
\text { POLIÁDICO/ } \\
\text { CRECHES } \\
\text { PÚBLICAS }\end{array}$} & \multicolumn{2}{|c|}{$\begin{array}{c}\text { CONTEXTO } \\
\text { POLIÁDICO/ } \\
\text { CRECHES } \\
\text { PARTICULARES }\end{array}$} & \multicolumn{2}{|c|}{ TOTAL } \\
\hline & $\mathrm{F}$ & $\%$ & $\mathrm{~F}$ & $\%$ & $\mathrm{~F}$ & $\%$ \\
\hline Fala espontânea & 58 & 9,61 & 71 & 10,64 & 129 & 10,15 \\
\hline Resposta verbal adequada & 198 & 32,85 & 188 & 28,18 & 386 & 30,4 \\
\hline Resposta verbal inadequada & 51 & 8,45 & 40 & 6 & 91 & 7,16 \\
\hline Resposta não verbal adequada & 41 & 6,8 & 65 & 9,8 & 106 & 8,34 \\
\hline Resposta não verbal inadequada & 15 & 2,5 & 33 & 4,94 & 48 & 3,8 \\
\hline Imitação & 35 & 5,8 & 13 & 1,94 & 48 & 3,8 \\
\hline Rir & 7 & 1,16 & 05 & 0,74 & 12 & 0,94 \\
\hline Apontar & 22 & 3,65 & 27 & 4,04 & 49 & 3,85 \\
\hline Olhar em direção ao adulto & 58 & 9,61 & 110 & 16,5 & 168 & 13,22 \\
\hline Vocalizações & 32 & 5,3 & 23 & 3,44 & 55 & 4,33 \\
\hline Repetição espontânea & 49 & 8,12 & 54 & 8,1 & 103 & 8,11 \\
\hline Autorrepetição & 19 & 3,15 & 11 & 1,64 & 30 & 2,36 \\
\hline Não resposta & 18 & 3 & 27 & 4,04 & 45 & 3,54 \\
\hline TOTAL & 603 & 100 & 667 & 100 & 1270 & 100 \\
\hline
\end{tabular}

Fonte: Santos, E.R.F. (2012). Concepções de Desenvolvimento Infantil e Estilos Comunicativos nas Interações Educador-Criança (Tese de doutoramento, Departamento de Psicologia, Universidade Federal da Paraíba, João Pessoa, Brasil).

É possível verificar, a partir da Tabela 2, que os Comportamentos comunicativos infantis originaram 13 categorias, que tiveram suas possíveis variações de frequências e percentuais considerados na análise dos dados. Logo, verificou-se que, entre os comportamentos comunicativos apresentados pelas crianças, a primeira categoria a se destacar foi a de Respostas verbais adequadas ( $f=386 ; 30,4 \%)$, tanto entre as crianças 
das creches públicas ( $f=198,32,85 \%$ ) quanto as crianças das creches particulares ( $f=188 ; 28,18 \%)$, tendo prevalecido também a Fala espontânea como terceira categoria de enunciados a emergir nas interações ( $f=129 ; 10,15 \%)$ e a Repetição espontânea $(f=103 ; 8,11 \%)$ como quinta categoria que se destacou entre os grupos de crianças.

Esses dados sugerem que as crianças apresentam linguagem compreensiva e verbal bem desenvolvida, o que se observa tanto entre as crianças das creches públicas quanto das particulares. Isso pode ser ilustrado também pelo fato de ambos os grupos de crianças terem apresentado baixas frequências de Resposta verbal inadequada $(f=91 ; 7,16 \%)$ e de Não resposta $(f=45 ; 3,54 \%)$.

Esses dados, de maneira geral, podem ser explicados pelo tipo de linguagem apresentado pelas educadoras de creches públicas e privadas estar associado à promoção do desenvolvimento linguístico infantil, principalmente a partir do elevado uso de Requisições de resposta geral, como ocorreu no presente estudo (Rivera et al., 2005). Considera-se também o uso dos Feedbacks e das Reformulações pelas educadoras desse estudo, que, embora tenha aparecido em menor frequência, ainda assim, conjuntamente com as Requisições, pode ter exercido uma influência sobre a promoção da linguagem expressiva das crianças (Girolametto et al., 2003; Milburn et al., 2013).

Outro comportamento comunicativo que se sobressaiu foi o Olhar em direção ao adulto. Este se configurou como a segunda categoria que mais emergiu nas interações entre as crianças das creches públicas $(f=58 ; 9,61 \%)$ e, sobretudo, entre as crianças das creches particulares ( $f=110 ; 16,5 \%$ ), o que pode ser um reflexo do elevado índice de Diretivos de atenção utilizados pelas educadoras das creches particulares, como também estar associado ao fato de o menor número de crianças por educadoras dessas creches particulares favorecer a interação.

Ainda com relação aos estilos comunicativos infantis, destaca-se que as crianças apresentaram uma frequência significativa de Resposta não verbal adequada ( $f=106$; $8,34 \%$ ), assim como certo destaque para o comportamento de Apontar ( $f=49 ; 3,85 \%$ ). Conjuntamente, as Respostas não verbais adequadas e os comportamentos comunicativos de Olhar em direção ao adulto e de Apontar podem significar que as crianças apresentam uma boa linguagem gestual, dado que pode ser confirmado pelo fato de tanto as crianças das creches públicas quanto as crianças das creches particulares terem apresentado baixas frequências de Resposta não verbal inadequada ( $f=48 ; 3,8 \%$ ).

Autores como Hunttenlocher, Vasilyeva, Cymerman e Levine (2002) discutiram, em seu estudo sobre input linguístico e habilidades sintáticas infantis, aspectos como o desenvolvimento da linguagem compreensiva das crianças, e, ao compararem os níveis de compreensão sintática entre crianças de baixo nível socioeconômico e crianças de alto nível socioeconômico, verificaram que não existia mudança substancial quanto ao desenvolvimento da linguagem compreensiva nos dois grupos. 
Vale destacar ainda que, no presente estudo, prevaleceu a linguagem compreensiva e verbal, em comparação com a linguagem gestual, nos dois grupos de crianças, o que sugere que há uma correlação com a complexidade da fala das educadoras. Nessa premissa, contrariamente ao estudo de Marinac, Ozanne e Woodyatt, (2000), as educadoras desta pesquisa demonstraram um comportamento comunicativo que pode ser considerado responsivo com as crianças, independentemente das interações terem ocorrido em contextos coletivos.

Por fim, é interessante pontuar também que esses dados corroboram com as compreensões de Hunttenlocher et al. (2002) sobre a prevalência do uso de sentenças complexas pelas educadoras como um aspecto que repercute sobre o desenvolvimento das habilidades sintáticas nas crianças.

\section{Considerações Finais}

O presente estudo possibilitou analisar as interações educador-crianças nos contextos interativos poliádicos de atividades de contar e recontar histórias infantis, em creches públicas e privadas. Essa temática teve como base teórica os pressupostos da Teoria Sócio-Histórica de Vigotski e a Perspectiva da Interação Social dos Estudiosos da Linguagem.

No que se refere aos Estilos comunicativos das educadoras, observou-se a predominância, nos dois grupos pesquisados, de um dos estilos considerados promotores do desenvolvimento linguístico, as Requisições, sobretudo das Requisições de resposta geral e das Requisições de resposta específica.

Outro ponto de destaque entre as educadoras das creches públicas e das creches particulares foram os Estilos comunicativos considerados pouco promotores do desenvolvimento da comunicação infantil, quais sejam os Assertivos e os Diretivos de atenção, devendo-se considerar a faixa etária das crianças e a proporção de crianças por educadora em relação ao uso dos diretivos.

Com relação à análise dos Comportamentos comunicativos infantis, prevaleceram as Respostas verbais adequadas em comparação com as Respostas não verbais adequadas. As Respostas verbais inadequadas e as Respostas não verbais inadequadas ocorreram em menor frequência, o que sugere um razoável desenvolvimento linguísti$\mathrm{co}$, tanto da linguagem expressiva quanto da linguagem compreensiva, por parte das crianças dos dois grupos de creches.

Desse modo, compreende-se que tais resultados apontam para as diferenças e semelhanças entre os dois grupos de educadoras, e que se destaca em ambos o uso de estratégias e rotinas que visam facilitar o desenvolvimento da linguagem infantil, apesar das limitações impostas pelo número de crianças por educadora. Entretanto, um ponto de diferença entre os dois grupos de educadoras, por exemplo, refere-se 
à formação dessas profissionais. No caso das creches públicas, verificou-se de que maneira repercutiu o preparo mais eficiente das mesmas na hora de contar e recontar as histórias infantis, não só em termos da frequência com que essas histórias ocorrem, como na utilização de recursos como fantasias e objetos referentes aos personagens das histórias contadas - importantes recursos para a promoção do imaginário infantil.

Nessa direção, ressalta-se que o educador tem uma responsabilidade direta em possibilitar trocas sociais com as crianças que priorizem o desenvolvimento infantil, contribuindo, entre outros aspectos, para a aquisição da linguagem por parte destas.

Portanto, com esta pesquisa, almeja-se contribuir com os estudos que já estão sendo realizados na área e com o planejamento de intervenções referentes à prática do educador de creche no contexto das interações com a criança.

\section{Referências}

Delgado, J. (2015). Entre os saberes e práticas das professoras de educação infantil: um estudo sobre os cuidados na primeira infância. Poiésis, 15 (9), 63-79.

Girolametto, L. \& Weitzman, E. (2002). Responsiveness of child care providers in interactions with toddlers and preschoolers. Language, Speech and Hearing Services in Schools, 33, 268-281.

Girolametto, L., Weitzman, E. \& Greenberg, J. (2003). Training day care staff to facilitate children's language. American Journal of Speech-Language Pathology, 12, 299-311.

Girolametto, L., Weitzman, E., Lieshout, R. V. \& Duff, D. (2000). Directiveness in teachers' language input to toddlers and preschoolers in day care. Journal of Speech, Language, and Hearing Research, 43, $1101-1114$

Hargrave, A. C. \& Sénéchal, M. (2000). A book reading intervention with preschool children who have limited vocabularies: the benefits of regular reading and dialogic reading. Early Childhood Research Quarterly, 15 (1), 75-90.

Hunttenlocher, J., Vasilyeva, M., Cymerman, E. \& Levine, S. (2002). Language input and child syntax. Cognitive Psychology, 45, 337-374.

Kelly, K. R \& Bailey, A. L. (2012). Becoming independent storytellers: modelling children's development of narrative macrostructure. First Language, 1 (33), 68-88.

Luo, Y., Snow, K. E., Chang, C. (2012). Mother-child talk during joint book reading in low-income American and Taiwanese families. First Language, 32 (4), 494-511.

Marinac, J. V., Ozanne, A. E. \& Woodyatt, G. C. (2000). Adult language input in the early childhood educational setting. Child Language Teaching and Therapy, 16 (2), 181-200.

Milburn, T. F., Girolametto, L., Weitzman, E. \& Greenberg, J. (2013). Enhancing Preschool Educators' Ability to Facilitate Conversations during Shared Book Reading. Journal of Early Childhood Literacy, 1 (14), 105-140.

Minayo, M. C. de S. (2010). O desafio do conhecimento: pesquisa qualitativa em saúde. (12a ed.). São Paulo: Hucitec. 
Santos, Ramos \& Salomão: Interações educador-crianças no contexto de creches públicas e privadas

Pessoa, L. \& Seidl, M. L. (2008). Características pragmáticas da fala materna em díades mãe-bebê (aos cinco meses). Arquivos Brasileiros de Psicologia, 1, 82-95.

Ramos, D. \& Salomão, N. M. R. (2012). Interação educadora-criança em creches públicas: estilos linguísticos. Psicologia em Estudo, 1 (17), 15-25.

Ramos, D. \& Salomão, N. M. R. (2016). Interação professora-criança em instituições de educação infantil: estilos linguísticos e habilidades sociocomunicativas. In Nádia M. R. S., Fabíola de S. B. e Mônica F. B. C. (Orgs.). Interface: psicologia do desenvolvimento e questões educacionais contemporâneas. João Pessoa-PB: Ed. UFPB.

Rescorla, L. (1989). The language development survey: a screening tool for delayed language in toddlers. Journal of Speech and Hearing Disorders, 54, 587-599.

Rivera, C., Girolametto, L., Greenberg, J. \& Weitzman, E. (2005). Childrens's Responses to educators' questions in day care play groups. American Journal of Speech-Language Pathology, 14, 14-26.

Salomão, N. M. R. (2010). Interação social e desenvolvimento linguístico. In Luna, Verônica L. do R. (Org.), Desafios da psicologia contemporânea. (pp.91-104). João Pessoa: Ed. Universitária da UFPB.

Salomão, N. M. R. (2012). Fala dirigida à criança. In: César Piccinini \& Patrícia Alvarenga (Org.), Maternidade e Paternidade: a parentalidade em diferentes contextos. São Paulo: Casa do Psicólogo.

Santos, E.R.F. (2012). Concepções de Desenvolvimento Infantil e Estilos Comunicativos nas Interações Educador-Criança (Tese de doutoramento, Departamento de Psicologia, Universidade Federal da Paraíba, João Pessoa, Brasil).

Santos, E. R. F., Ramos, D. D. \& Salomão, N. M. R. (2015). Concepções sobre desenvolvimento infantil na perspectiva de educadoras em creches públicas e privadas. Revista Portuguesa de Educação, 28 (2), 189-209.

Snow, C. E. (1997). Questões no estudo do input: sintonia, universalidade, diferenças individuais e evolutivas, e causas necessárias. In P. Fletcher \& B. MacWhitnney (Orgs.), Compêndio da linguagem da criança (pp. 153-163). Porto Alegre: Artes Médicas.

Stich, M., Girolametto, L., Johnson, C. J., Cleave, P. L. \& Chen, X. (2013). Contextual effects on the conversations of mothers and their children with language impairment. Applied Psycholinguistics, 3, 1-22.

Sokolov, J. \& Snow, C. (1994). Handbook of Research in Language Development Sing Childes. Hillsdale, $\mathrm{NJ}$ : Erlbaum.

Tamis-LeMonda, C. S, Baumwell, L. \& Cristofaro, T. (2012). Parent-child conversations during play. First Language, 32, (4), 413-438.

Vygotsky, L. S. (2007). A Formação Social da Mente. São Paulo: Martins Fontes (1ª ed. 1978). 
Ellis Regina Ferreira dos Santos Doutora em Psicologia Social - Universidade Federal da Paraíba, Brasil Docente no Departamento de Ciências Humanas e suas Tecnologias do Instituto Federal de Educação, Ciência e Tecnologia da Paraíba, Brasil

Email: ellisrf@yahoo.com.br

ORCID: http://orcid.org/0000-0001-8775-7046

Deborah Dornellas Ramos

Doutora em Psicologia Social - Universidade Federal da Paraíba, Brasil

Docente do Centro de Educação e Saúde da Universidade Federal de Campina Grande, Brasil

Email: deborahdornellas@gmail.com ORCID: http://orcid.org/0000-0001-7865-5945

Nádia Maria Ribeiro Salomão

Doutora em Psicologia - University of Manchester. Docente do Departamento de Psicologia, Universidade Federal da Paraíba,

Brasil Email:nmrs@uol.com.br

ORCID: http://orcid.org/0000-0003-1305-7762

Correspondência

Ellis Regina Ferreira dos Santos

Rua Francisco Alves, n 655, Bairro Presidente Médici

Campina Grande, Paraíba, Brasil. CEP: 58417-603.

Data de submissão: Março 2018

Data de avaliação: Maio 2018

Data de Publicação: Dezembro de 2019 